\title{
Antinociceptive and anti-inflammatory activities of the aqueous leaf extract of Erlangea tomentosa (Asteraceae) in rats and mice
}

\author{
Isaac MUHWANA ${ }^{1}$, Samuel Baker OBAKIRO ${ }^{1}$, Ivan IBANDA ${ }^{1}$, Pender Gift CRUCIFIX ${ }^{1}$, \\ Adam Moyosore AFODUN ${ }^{2}$ and Saidi ODOMA ${ }^{1,3 *}$ \\ ${ }^{1}$ Department of Pharmacology and Toxicology, School of Pharmacy, Kampala International University, Western \\ Campus, Ishaka-Bushenyi, Uganda. ${ }^{2}$ Department of Anatomy, Faculty of Biomedicals, Kampala International \\ University, Western Campus, Ishaka-Bushenyi, Uganda. ${ }^{3}$ Department of Pharmacology and Therapeutics, \\ Faculty of Basic Clinical Sciences, College of Health Sciences, Kogi State University, Anyigba, Nigeria.
}

Received 27th August 2019; Accepted $1^{\text {st }}$ February 2020

\begin{abstract}
Erlangea tomentosa (Asteraceae) is used traditionally in the preparation of herbal remedies for management of several diseases including pain and inflammation. However, its efficacy and safety have not been scientifically validated. The aim of this study was to investigate the antinociceptive and anti-inflammatory activities of the aqueous leaf extract of this plant and its acute toxicity profile in animal models. Antinociceptive activity and anti-inflammatory activity were determined using the acetic acid-induced writhing model in mice and carrageenan induced inflammation model in rats respectively. The oral median lethal dose $\left(\mathrm{LD}_{50}\right)$ was determined using the Lorke's Method. The extract inhibited pain due to acetic acid significantly $(p<0.05)$ at doses of $250 \mathrm{mg} / \mathrm{kg}$ and $500 \mathrm{mg} / \mathrm{kg}$. The inflammation due to carrageenan was also significantly $(p<0.05)$ reduced at dose of $500 \mathrm{mg} / \mathrm{kg}$ body weight but not $250 \mathrm{mg} / \mathrm{Kg}$. The LD $\mathrm{LD}_{50} \mathrm{value}$ of the extract was greater than $5,000 \mathrm{mg} / \mathrm{kg}$ implying that the extract was safe in 24 hours when administered in a single high oral dose. Preliminary phytochemical screening revealed the presence of alkaloids, anthraquinones, coumarins, saponins, tannins and resins. The present study has demonstrated the antinociceptive and anti-inflammatory potential of aqueous leaf extract of Erlangea tomentosa in rats and mice; thus validates the folkloric use of the plant.
\end{abstract}

Keywords: Erlangea tomentosa; Antinociception; Anti-inflammation; Acetic acid; Carrageenan

\section{INTRODUCTION}

Inflammatory diseases and pain are a common cause of morbidity and mortality worldwide [1]. Therapeutic management of these conditions involve the use of nonsteroidal anti-inflammatory drugs, corticosteroids and opioid analgesics [2]. All these drugs are associated with severe adverse drug reactions, expensive and some cause dependence [2]. This in addition to limited access to primary health care in developing countries has resulted into widespread of herbal medicines due to the availability, accessibility, affordability and cultural acceptance across different ethnic backgrounds [3-5].

Erlangea tomentosa (Oliv. \& Hiern) S. Moore (Asteraceae) is an erect woody herb that

\footnotetext{
*Correspondence. E-mail: odomasaeed@gmail.com Tel: +234-8027547778, +256-753648474 ISSN 0189-8442

2020 Published by Faculty of Pharmaceutical Sciences, University of Jos, Nigeria. Under Creative Commons Attribution-NonCommercial 4.0 International License. https://creativecommons.org/licenses/by-nc/4.0/
} 
grows up to $50 \mathrm{~cm}$ high. It is known as Ekyoganyanja in Runyankore [4]. The leaves of this plant are widely used by traditional herbal medicine practitioners to prepare herbal remedies for management of various ailments. These include stomachache, colic pains, syphilis, miscarriage fever [5], diarrhoea, skin infections, anaemia, appetite boosting, syphilis [3], conjunctivitis, convulsion in children, and mental confusion [6]. The diverse bioactivity of this plant has been attributed to presence of phytochemicals such as tannins, flavonoids, anthocyanins, saponins, coumarins and steroid glycosides [6,7].

Despite the widespread use of $E$. tomentosa in preparation of herbal medicines for management of pain and inflammation, there was paucity of scientific data regarding its antinociceptive and anti-inflammatory activity. Therefore, the aim of this study was to validate the above claimed bioactivity so as to increase confidence among traditional medicine practitioners and also provide alternative source of molecules for development of better anti-inflammatory and analgesic agents.

\section{EXPERIMENTAL}

Collection, identification and preparation of plant materials. The leaves of Erlangea tomentosa were collected from Rukararwe Eco Centre, Bushenyi district, in September 2018. The plant was identified by Dr. Eunice Olet, a botanist and the Head of the Department of Botany, Mbarara University of Science and Technology, Uganda. A voucher specimen number (50891) was deposited in the national herbarium at Makerere University Botany Department, Uganda for future reference. The leaves were air-dried for 14 days until crimpy and then grounded into fine powder by using a mortar and pestle. About 250 grams of the powder was macerated in 2 liters of distilled water for 24 hours. The mixture was then filtered using Whatman filter paper. The filtered extract was then freeze-dried in $200 \mathrm{ml}$ portions using a Freeze Dryer (ModulyoEdwards). The freeze-dried powder was then pooled together into airtight containers, weighed and stored at room temperature $\left(23^{\circ} \mathrm{C}\right.$ approx.) until ready for use.

Phytochemical screening. Phytochemical screening was conducted as described by Trease and Evans [8] to identify the different classes of phytochemicals present in the extract.

Animals and ethical consideration. Ethical approval was sought and granted from the school of Pharmacy research committee and the institution research and Ethics committee of Kampala International University. Adult Wistar albino rats $(120-170 \mathrm{~g})$ and Swiss Albino mice (20-30g) of both sexes were obtained from the animal house facility at the Department of Pharmacology and Toxicology, Kampala International University, Western Campus (KIU-WC). The animals were maintained in standard cages under standard environmental conditions of temperature, humidity and illumination cycle. The animals were fed with standard rodent pellet diet and water ad libitum. Animal welfare and rights were ensured as described in the Guide for the Care and Use of Laboratory Animals by the National Institutes of Health (Publication No. 80-23, revised 1996).

Acute toxicity studies. The oral median lethal dose $\left(\mathrm{LD}_{50}\right)$ of the extract was estimated using a biphasic method as previously described by Lorke [9]. In the first phase, three groups of three mice each were administered with the extract 10,100 and $1,000 \mathrm{mg} / \mathrm{kg}$. The animals were observed for signs of toxicity and death for the first 2 hours and intermittently for 24 hours. In the second phase, three mice were each administered with the extract at 1600, 2,900 and $5,000 \mathrm{mg} / \mathrm{kg}$. They were also observed for signs of toxicity and death for the first 2 hours and intermittently for 24 hours. The $\mathrm{LD}_{50}$ value was estimated by calculating the geometric mean of the lowest dose that 
caused death and the highest dose for which the animals survived.

Evaluation of antinociceptive activity in mice. Four (4) randomly selected groups of mice $(n=5)$ were orally administered with distilled water $(10 \mathrm{ml} / \mathrm{kg})$, acetylsalicylic acid (ASA, $300 \mathrm{mg} / \mathrm{kg}$ ) and the plant extract $(250$ and $500 \mathrm{mg} / \mathrm{kg}$ ). Sixty minutes after oral administration, acetic acid $0.6 \% \mathrm{v} / \mathrm{v}(10 \mathrm{ml} / \mathrm{kg})$ was administered intraperitoneally to each mouse and was placed in observation cage. Five minutes post acetic acid injection, the number of writhes was counted for each mouse for a period of 10 minutes. A reduction in the number of writhes as compared to the distilled water treated animals was considered as evidence for the presence of antinociception and expressed as percent inhibition of writhes [10].

$\%$ Inhibition $=$

$\frac{\text { Mean No. of writhes (D/Water) }- \text { Mean No. of writhes (Test) }}{\text { Mean No. of writhes (D/Water) }} \times 100$

Evaluation of anti-inflammatory activity in rats. Four (4) randomly selected groups of rats $(n=5)$ were orally administered distilled water $(1 \mathrm{ml} / \mathrm{kg})$, Acetylsalicylic acid $(300 \mathrm{mg} / \mathrm{kg})$, and extract $(250$ and $500 \mathrm{mg} / \mathrm{kg})$. Sixty minutes post treatment, each rat was injected with $0.1 \mathrm{ml}$ of $1 \%$ carrageenan into plantar surface of rat right hind paw. The hind paw oedema was measured and recorded at times 0 , 1, 2, 3 and 4 hours using Vernier caliper to determine the diameter of the oedema. The increase in paw diameter (oedema index) for each rat was calculated as the difference in paw diameter before carrageenan injection and after carrageenan injection at each time interval [11]. The percent inhibition of oedema was calculated for each group with respect to its distilled water treated control group using the following relationship:

$\frac{\text { Mean paw oedema (D/Water) }- \text { Mean paw oedema }(\text { Test })}{\text { Mean paw oedema }(\mathrm{D} / \text { Water })} \times 100$
Data management and analysis. All numerical values were expressed as Mean \pm Standard Error of the Mean (SEM). The data were analyzed by one-way analysis of variance (ANOVA) followed by Dunnett's Post hoc test for Multiple Comparison, using the Graph Pad Prism (statistical) software. The differences between means were considered significant when $p<0.05$.

\section{RESULTS AND DISCUSSION}

This study was designed to investigate the antinociceptive and anti-inflammatory activities of the aqueous leaf extract of Erlangea tomentosa. The oral median lethal dose of the plant extract was greater than 5,000 $\mathrm{mg} / \mathrm{kg}$. Administration of doses of the aqueous extract of doses up to $5,000 \mathrm{mg} / \mathrm{kg}$ caused no death and no observable signs of toxicity. This suggests that the aqueous leaf extract of $E$. tomentosa was relatively safe [12].

The intraperitoneal injection of acetic acid elicited the writhing syndrome in control mice with $37.2 \pm 12.60$ writhes counted in 10 min. The extract produced a significant $(p<$ $0.05)$ reduction in the number of writhes with peak effect of $63.44 \%$ inhibition at the dose $250 \mathrm{mg} / \mathrm{kg}$ (Figure 1). These results are similar to other previous studies on evaluation of antinociceptive activities of medicinal plant extracts in laboratory animals [13]. There was no significant difference in the percentage inhibition of writhes between 250 and 500 $\mathrm{mg} / \mathrm{kg}$. This implies that antinociceptive activity was not dose dependent. The oedema ensued secondary to the carrageenan injection. The dose of $500 \mathrm{mg} / \mathrm{kg}$ body weight showed a significant anti-inflammatory activity $(p<0.05)$ at the 1st and 2nd hours after injection while the lower dose of $250 \mathrm{mg} / \mathrm{kg}$ was not as effective. The percentage inhibitions of $46.43 \%, 44.71 \%, 30.99$ and $35.56 \%$ were observed at the 1st, 2nd, 3rd and 4th hour respectively with the dose of $500 \mathrm{mg} / \mathrm{kg}$ (Figure 2). The anti-inflammatory activity of the extract against carrageenan-induced 
I. Muhwana et al. / J. Pharmacy \& Bioresources 17(1), 19-23 (2020)

inflammation was therefore dose dependent. The ineffectiveness of the $250 \mathrm{mg} / \mathrm{kg}$ dose could be attributed to insufficient concentration of the active secondary metabolites [14].

The preliminary phytochemical screening revealed the presence of alkaloids, anthraquinones, coumarins, saponins, tannins and resins. The antinociceptive and anti- inflammatory effects of extract could be attributed to one or more of these observed phytoconstituents. Odoma et al. [12] reported that tannins, alkaloids and saponins possess antinociceptive and anti-inflammatory activities. However, the study could not identify the real phytochemicals responsible for the observed activity.

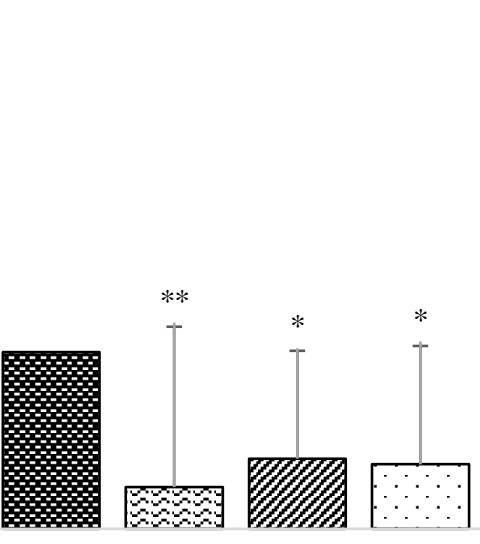

Mean Number of Writhes

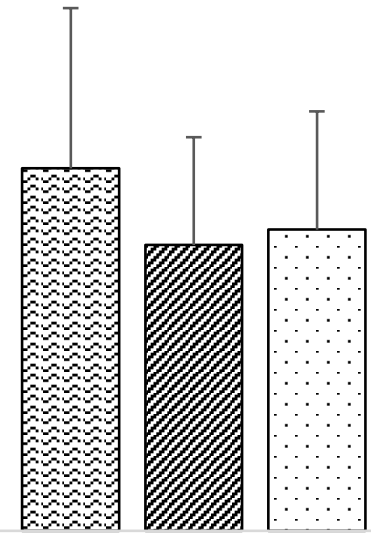

Percentage Inhibition (\%)

Figure 1: Effect of aqueous leaf extract of E. tomentosa on acetic acid-induced writhes in mice $* *=p<0.01, *=p<0.05$ compared to distilled water treated group. ASA $=$ Acetylsalicylic acid, $\mathrm{AEET}=$ Aqueous extract of Erlangea tomentosa, $\mathrm{n}=5$

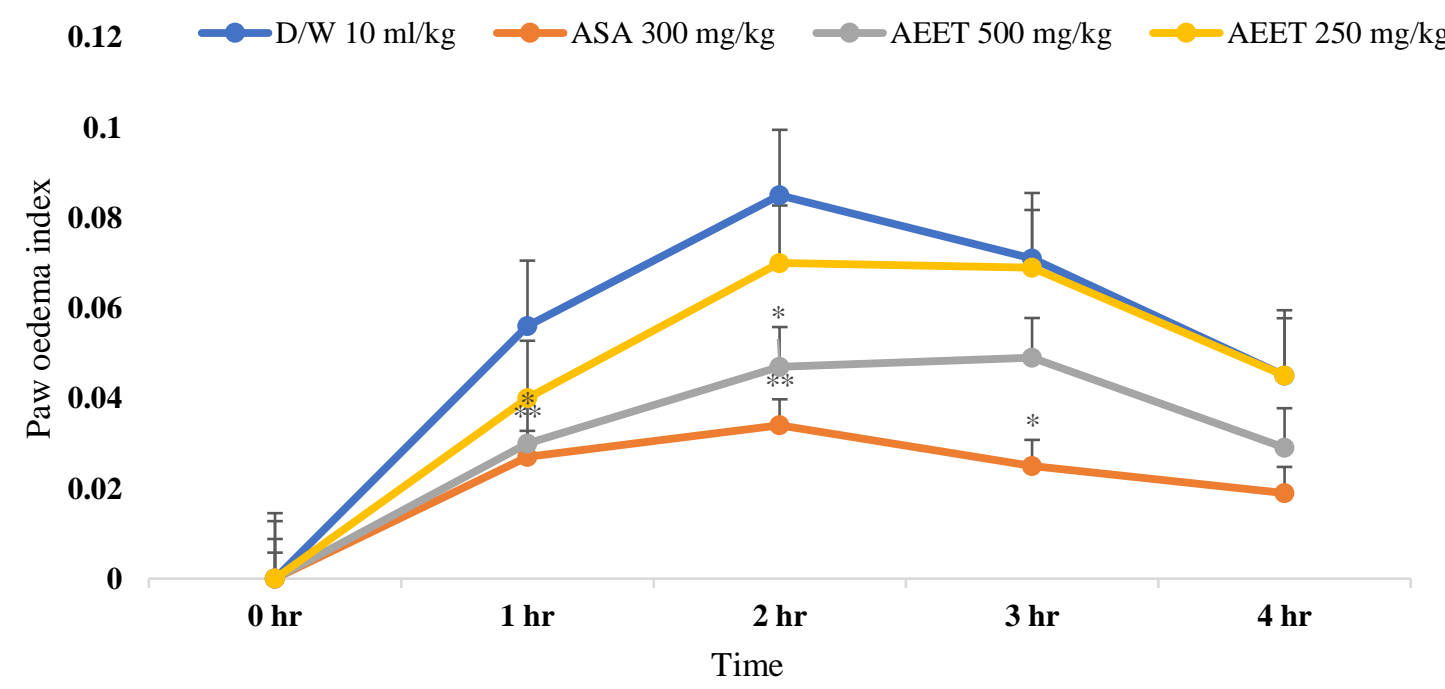

Figure 2: Effect of aqueous leaf extract of E. tomentosa on carrageenan induced oedema in rats. $*_{*}^{*}=\mathrm{p}<0.01, *=\mathrm{p}<0.05$ compared to distilled water treated group. ASA= Acetylsalicylic acid, $\mathrm{AEET}=$ Aqueous extract of Erlangea tomentosa, $\mathrm{n}=5$. 
Conclusion. The data suggest that the aqueous leaf extract of Erlangea tomentosa possesses antinociceptive and anti-inflammatory activities and is relatively safe when orally administered in a single dose within 24 hours. This therefore further support the ethnomedical use of the plant in the management of pain and inflammatory conditions. We recommend more studies to isolate and characterize the pure chemical compounds in this plant responsible for this confirmed bioactivity and establish the exact mechanism through which the extract exacts its antinociceptive and anti-inflammatory activity.

Acknowledgments. Authors are thankful to Mr. Charles Kamusiime for taking care of the animals before and during the study. We are also thankful to the technical staff of the Department of Pharmacology and Toxicology and the School of Pharmacy, Kampala International University, Western Campus, for their technical support during the study.

\section{REFERENCES}

1. Owor, Richard Oriko, Kibrom Gebreheiwot Bedane, Sebastian Zühlke, Solomon Derese, George Otieno Ong'amo, Albert Ndakala, and Michael Spiteller. 2020. "Anti-Inflammatory Flavanones and Flavones from Tephrosia Linearis." Journal of Natural Products.

https://doi.org/10.1021/acs.jnatprod.9b00922.

2. Katzung, B.G, S.B Masters, and A.J Trevor. 2012. Basic \& Clinical Pharmacology. 12th ed. The McGraw Hill Companies.

3. Asiimwe, S., Kamatenesi-Mugisha, M., Namutebi, A., Borg-Karlsson, A.K., Musiimenta, P., (2013); Ethnobotanical study of nutri-medicinal plants used for the management of HIV/AIDS opportunistic ailments among the local communities of western Uganda, Journal of Ethnopharmacology, 150, 639648.

4. Asiimwe, S., Namutebi, A., Borg-Karlsson, A., Kamatenesi, M.M., Oryem-Origa, H., (2014); Documentation and consensus of indigenous knowledge on medicinal plants used by the local communities of western Uganda, J. Nat. Prod. Plant Resour. 4, 34-42.

5. Adaku, C., Irene, S., Helge, B., Robert, B., Monica, J., Øyvind, M.A. (2019); Anthocyanins from mauve flowers of Erlangea tomentosa (Bothriocline longipes) based on erlangidin - The first reported natural anthocyanidin with C-ring methoxylation, Phytochemistry Letters, 29: 225-230.

6. Asiimwe S. (2015); Nutri-medicinal Plants Used in the Management of HIV/AIDS Opportunistic Infections in Western Uganda: Documentation, Phytochemistry and Bioactivity Evaluation (Eds), TRITA-CHE Report 2015:34 Printed by Universities service US-AB Stockholm- Germany, 81pgs.

7. Nostro, A.M.P., Germano, Á.V., D'Angelo, A., Marino and Cannatelli, M.A. (2000). Extraction methods and bioautography for evaluation of medicinal plant antimicrobial activity, Letters in Applied Microbiology, 30:379-384.

8. Evans, W.C., (2009); Trease and Evans Pharmacognosy, 16th edition. Elsevier Saunders.

9. Lorke, D. (1983); A new approach to acute toxicity testing. Archives of toxicology, 54: 275-287.

10. Koster R, Anderson M. and De Bear E.J., (1959); Acetic acid for analgesic screening, Federation Proceedings, 18: 412- 416.

11. Winter, C.A., Risley, E.A. and Nuss, G.W. (1962), Carrageenan induced edema in hind paw of the rat as an assay for anti-inflammatory drugs, Proceedings of the Society for Experimental Biology and Medicine, 111: 544-547.

12. Odoma, S., Zezi, A.U., Danjuma, N.M., Ahmed, A. (2014); Analgesic and anti-inflammatory properties of methanol leaf extract of Olax subscorpioidea Oliv. (Olacaceae) in mice and rats, J. Pharmacol. Trop. Ther, 4 (1), 29-37.

13. Mahnaz, K., Mohammad-reza, D., Vahid, N., Sattar, O. and Azam, B. (2012); Evaluation of analgesic effects of hydroalcoholic extract of Marrubium parviflorum by formalin test in mice, Asian Journal of plant sciences, 11(12):96-99.

14. Gitahi, S.M., Juma, K.K., Mworia, J.K., Aliyu U., Mwonjoria, K.J., John N., Anne, W., Mburu, N.D. and Ngugi M.P., (2015); Antinociceptive properties of dichloroethane: methanolic leaf and root bark extracts of Carissa edulis in rats, Journal of Phytopharmacology, 4(2):106-112. 